\title{
Molecular profile of KRAS G12C-mutant colorectal and non-small-cell lung cancer
}

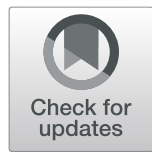

\author{
Luiz Henrique Araujo ${ }^{1,2,3,4^{*}}$, Bianca Mendes Souza', Laura Rabelo Leite', Sabrina A. F. Parma', Natália P. Lopes ${ }^{1}$,
} Frederico S. V. Malta ${ }^{2}$ and Maíra C. M. Freire ${ }^{1}$

\begin{abstract}
Background: KRAS is the most frequently mutated oncogene in cancer, however efforts to develop targeted therapies have been largely unsuccessful. Recently, two small-molecule inhibitors, AMG 510 and MRTX849, have shown promising activity in KRAS G12C-mutant solid tumors. The current study aims to assess the molecular profile of KRAS G12C in colorectal (CRC) and non-small-cell lung cancer (NSCLC) tested in a clinical certified laboratory.

Methods: CRC and NSCLC samples submitted for KRAS testing between 2017 and 2019 were reviewed. CRC samples were tested for KRAS and NRAS by pyrosequencing, while NSCLC samples were submitted to next generation sequencing of KRAS, NRAS, EGFR, and BRAF.

Results: The dataset comprised 4897 CRC and 4686 NSCLC samples. Among CRC samples, KRAS was mutated in 2354 (48.1\%). Most frequent codon 12 mutations were G12D in 731 samples (14.9\%) and G12V in 522 (10.7\%), followed by G12C in 167 (3.4\%). KRAS mutations were more frequent in females than males ( $p=0.003)$, however this difference was exclusive of non-G12C mutants $(p<0.001)$. KRAS mutation frequency was lower in the South and North regions ( $p=0.003)$, but again KRAS G12C did not differ significantly $(p=0.80)$. In NSCLC, KRAS mutations were found in 1004 samples (21.4\%). As opposed to CRC samples, G12C was the most common mutation in KRAS, in 346 cases (7.4\%). The frequency of KRAS G12C was higher in the South and Southeast regions $(p=0.012)$, and lower in patients younger than 50 years $(p<0.001)$. KRAS G12C mutations were largely mutually exclusive with other driver mutations; only 11 NSCLC (3.2\%) and 1 CRC (0.6\%) cases had relevant co-mutations.

Conclusions: KRAS G12C presents in frequencies higher than several other driver mutations, and may represent a large volume of patients in absolute numbers. KRAS testing should be considered in all CRC and NSCLC patients, independently of clinical or demographic characteristics.
\end{abstract}

Keywords: Lung neoplasms, Colorectal neoplasms, KRAS, Molecular targeted therapy, Molecular diagnostics

\section{Introduction}

The field of precision oncology has revolutionized the way cancer is approached in the past two decades [1-3]. Throughout the years, numerous compounds have been developed targeting proteins responsible for the development and maintenance of cancer cells, with relevant

\footnotetext{
* Correspondence: luizaraujo.md@gmail.com

${ }^{1}$ Progenética, Grupo Pardini, Vespaziano, Brazil

2Research \& Development Sector, Grupo Pardini, Vespaziano, Brazil

Full list of author information is available at the end of the article
}

implications in the clinic. In parallel, a better understanding of cancer biology and genetics enabled researchers to define predictive biomarkers that help oncologists select the most suitable targeted therapies for patients [4].

$R A S$ genes were identified as the first oncogenes in 1982; specifically a single missense mutation in $H R A S$ codon 12 was found in a bladder carcinoma cell line [5, 6]. Subsequently, the somatic origin of RAS mutations was confirmed, three isoforms were described and hotspots were found at codons 12,13 , and $61 . K R A S$ is the

C C The Author(s). 2021 Open Access This article is licensed under a Creative Commons Attribution 4.0 International License, which permits use, sharing, adaptation, distribution and reproduction in any medium or format, as long as you give appropriate credit to the original author(s) and the source, provide a link to the Creative Commons licence, and indicate if changes were made. The images or other third party material in this article are included in the article's Creative Commons licence, unless indicated otherwise in a credit line to the material. If material is not included in the article's Creative Commons licence and your intended use is not permitted by statutory regulation or exceeds the permitted use, you will need to obtain permission directly from the copyright holder. To view a copy of this licence, visit http://creativecommons.org/licenses/by/4.0/ The Creative Commons Public Domain Dedication waiver (http://creativecommons.org/publicdomain/zero/1.0/) applies to the data made available in this article, unless otherwise stated in a credit line to the data. 
most frequently mutated oncogene in cancers, with mutation rates of up to $96 \%$ in pancreatic cancers $[7,8]$, $54 \%$ in colorectal cancers (CRC) $[9,10]$, and $39 \%$ in lung adenocarcinomas [11]. RAS proteins belong to a superfamily of small GTPases that regulate fundamental intracellular signaling pathways involved in cell growth and survival $[12,13]$. RAS missense mutations stabilize the protein in its active, GTP-bound state, which leads to sustained transduction of pathways including the MAPK [14-16].

In $\mathrm{CRC}$, it has been demonstrated that $R A S$ mutations are associated with lack of response to monoclonal antibodies against the epidermal growth factor receptor (EGFR), an upstream target related to RAS [17]. RAS testing is currently required in metastatic CRC in order to rule out the presence of missense mutations, and select patients for anti-EGFR antibodies [17]. In non-small cell lung cancer (NSCLC), RAS mutations have also been related to limited benefit from EGFR tyrosine kinase inhibitors [18]. Subsequently, EGFR mutations per se were shown to determine sensitivity to these inhibitors, and are mostly mutually exclusive with RAS [2]. Several other genomic alterations have been shown to determine sensitivity to specific targeted therapies in NSCLC [19]. Routine testing of gene mutations or fusions involving EGFR, ALK, RET, ROS1, MET, BRAF, ERBB2, and NTRK are recommended to select patients for targeted therapy [20].

KRAS G12C mutant has been exploited as a potential target for novel therapies. Indeed, the codon 12 cysteine residue may serve as a binding pocket for covalent inhibitors, stabilizing KRAS in an inactive, GDP-bound form [21]. Two novel compounds have been developed to act against KRAS G12C and are under clinical development, sotorasib (AMG 510) [21] and adagrasib (MRTX849) [22]. Understanding the frequency of KRAS G12C and co-occurring mutations is crucial to define strategies for cancer control. Herein we present a large review of CRC and NSCLC tumor samples submitted for KRAS testing in a clinical certified laboratory.

\section{Materials and methods}

\section{Study design}

We retrospectively analyzed deidentified data from CRC and NSCLC tumor samples submitted to KRAS testing in a clinical certified laboratory (Progenética, Grupo Pardini - Brazil) between 2017 and 2019. Available clinical data were reviewed and annotated. No patient had duplicated tumor samples analyzed. Samples were previously acquired for clinical purpose, included either biopsy or resection, and were all preserved in formalin-fixed paraffin-embedded (FFPE) tissue blocks. Following the laboratory routine, tumor slides were examined to confirm sample diagnosis and adequacy for sequencing. At least two 4-6 micra tumor slides were required, with tumor content of $5 \%$ or more. DNA was extracted using an automated protocol (QIAsymphony DSP DNA Mini Kit, Qiagen; Hilden, Germany), and quantified using the Qubit 2.0 fluorometer (Thermo Fisher Scientific, Waltham, Massachusetts, US). A minimum of $10 \mathrm{ng}$ of genomic DNA was required for targeted sequencing.

CRC samples were tested for KRAS and NRAS mutations using pyrosequencing (Therascreen KRAS Pyro Kit and Therascreen RAS Extension Pyro Kit, Qiagen; Hilden, Germany), while NSCLC samples were tested for $K R A S, N R A S, B R A F$, and EGFR by next generation sequencing (NGS; Thermo Fisher Technology; Waltham, Massachusetts, United States). Co-occurring mutations were confirmed by an orthogonal method. The pyrosequencing was performed according to handbooks of Kits' manufacturer (Therascreen KRAS Pyro $^{\circ}$ Handbook and Therascreen RAS Extension Pyro ${ }^{\circ}$ V2 Kit Handbook). The following hotspot sites mutations were analyzed for KRAS and NRAS: codons 12-13, 61, 117 and 146. Reactions were run in the PyroMark Q24 instrument (Qiagen; Hilden, Germany) and analyzed using the software v2.0.7 in default mode. The NGS panel was customized to cover 17 amplicons of interest in hotspot regions at: EGFR exons 18 (codons 696-725), 19 (codons 729-761), 20 (codons 762-796 and 808-823) and 21 (codons 856875); KRAS exons 2 (codons 6-37), 3 (codons 38-65) and 4 (codons 114-149); NRAS exons 2 (codons 4-30), 3 (codons 43-68) and 4 (codons 125-150); and BRAF exons 11 (codons 439-472) and 15 (582-610).

For NGS analysis, raw sequence data were mapped to the hg19 human reference genome using Torrent Mapping Alignment Program aligner. Torrent Coverage Analysis Plugin implemented in v5.0 of the Torrent Suite software (Thermo Fisher Scientific) was used to perform initial quality control and used to assess amplicon coverage for regions of interest. Regions were obtained after filtering of uniformity (>80\%), on-target reads $(>50 \%)$ and minimum mapped reads of 25.000. Variant calling was carried out using Ion Reporter v5.0 (Thermo Fisher Scientific) with the default setting of somatic parameters (minimum variant quality of 10 , minimum coverage of $5 \times$, maximum strand bias of 0.95 , and minimum variant score of 6 ). The lowest limit of detection for low-frequency variants was $5 \%$. Variants were annotated using the following databases: 5000Exomes V.1, Canonical RefSeq Transcripts v63, ClinVar v.1, COSMICv.67, dbSNP v.138, DGV v.20130723, DrugBank v.1, Gene Ontology, v. 1.218, OMIM v.03022014, Pfam v.26, PhyloP Scores v.1, RefSeq Functional Canonical Transcripts Scores v.4 RefSeq GeneModel v. 63. All identified variants were checked for correct nomenclature viewing the Integrative Genomics Viewer (IGV) alignment. 


\section{Statistical analysis}

Clinical and molecular data (age, gender, geographic region, histology, and mutation status) are described in absolute numbers and frequencies. Age is also provided as mean and standard error (SE). Categorical variables were compared using Pearson's Chi-square test. KRAS status was classified as G12C mutant, non-G12C mutant ("KRAS Others"), and wild type. All comparisons included two-tailed tests, with level of significance set at $5 \%$. All analyses were performed using IBM SPSS software (version 26.0; IBM Corporation, Armonk, NY, USA). All methods were carried out in accordance with relevant guidelines and regulations.

\section{Ethical considerations}

The protocol was reviewed and approved by local Ethics Committee (Research Ethics Committee of the Minas Gerais Social Security Institute - IPSEMG). A waiver for the informed consent was also approved by the Research Ethics Committee of the Minas Gerais Social Security Institute since all patients had previously signed an authorization for testing, and data were collected retrospectively through molecular reports review. No information capable of identifying patients was used.

\section{Results}

\section{Patient and sample characteristics}

The dataset comprised 4897 CRC and 4686 NSCLC samples (Table 1). Mean age was 59.8 years (SE 0.186) and 65.6 years (SE 0.170) among CRC and NSCLC patients, respectively. Patient cases were well balanced according to gender in both cohorts (51.8 and 45.7\% males, respectively). Brazilian Southeast and South regions were the most frequently represented, however all regions were present in the complete dataset. Adenocarcinoma was the most frequent histological subtype in both cases (87.8 and $81.4 \%$, respectively). All KRAS G12C mutations were caused by a c.34G $>\mathrm{T}$ missense mutation.

\section{Tumor genotyping}

Among 4897 CRC samples tested, KRAS was mutated in 2354 (48.1\%). Most frequent hotspots were at codon 12 in 1696 samples (34.6\%), codon 13 in 403 (8.2\%), and codon 61 in 116 (2.4\%). Most frequent codon 12 mutations were G12D in 731 samples (14.9\%) and G12V in $522(10.7 \%)$, followed by G12C in 167 samples (3.4\%) (Figs. 1 and 2). Patients with KRAS G12C had a mean age of 60.2 years (SE 1.061), and were well distributed according to gender (51.9\% males). The presence of $K R A S$ mutations was significantly higher among females than males ( $50.5 \%$ vs $45.8 \% ; p=0.003)$, however this difference was exclusive of non-G12C mutants $(p<0.001)$. KRAS mutation frequency was significantly lower in the
Table 1 Patient and sample characteristics

\begin{tabular}{lll}
\hline Characteristics & $\begin{array}{l}\text { CRC } \\
(\boldsymbol{N}=\mathbf{4 8 9 7})\end{array}$ & $\begin{array}{l}\text { NSCLC } \\
(\boldsymbol{N}=\mathbf{4 6 8 6})\end{array}$ \\
\hline $\begin{array}{lll}\text { Age (years), N (\%) } \\
<40\end{array}$ & $339(6.9)$ & $97(2.1)$ \\
$40-49$ & $661(13.5)$ & $302(6.5)$ \\
$50-59$ & $1241(25.3)$ & $922(19.7)$ \\
$60-69$ & $1530(31.2)$ & $1572(33.7)$ \\
$>70$ & $1126(23.0)$ & $1776(38.0)$ \\
Gender, N (\%) & & \\
Male & $2535(51.8)$ & $2142(45.7)$ \\
Female & $2362(48.2)$ & $2544(54.3)$ \\
Region, N (\%) & & $2599(55.5)$ \\
Southeast & $3614(73.8)$ & $672(14.3)$ \\
South & $641(13.1)$ & $769(16.4)$ \\
Northeast & $133(2.7)$ & $449(9.6)$ \\
Middle West & $407(8.3)$ & $197(4.2)$ \\
North & $102(2.1)$ & $648(13.8)$ \\
Histology, N (\%) & & $3814(81.4)$ \\
Adenocarcinoma & & $19(0.4)$ \\
Squamous cell carcinoma & - & $205(4.4)$ \\
NSCLC NOS & - & \\
Unknown & $597(12.2)$ & $(87.8)$ \\
\hline
\end{tabular}

Abbreviations: CRC colorectal cancer; NSCLC non-small cell lung cancer; NOS not otherwise specified. Obs seventeen NSCLC cases lacked information on age; hence only valid percentage is presented

South and North regions (42.4 and 36.3\%, respectively; $p=0.003)$, but again KRAS G12C did not differ significantly $(p=0.80)$. The frequency of KRAS G12C varied from $2.9 \%$ in the Middle West to $3.9 \%$ in the North. No association was seen between KRAS status and age ( $p=$ 0.481 ). The frequency of KRAS G12C varied from $2.6 \%$ for patients aged $40-49$ years to $3.8 \%$ for patients younger than 40 (Fig. 3 and Supplemental Table 1).

Among 4686 NSCLC samples, KRAS mutations were found in 1004 (21.4\%), mostly at codon 12 in 875 (18.7\%) and codon 13 in 64 (1.4\%). The distribution of KRAS G12 mutations was significantly distinct from CRC data ( $p<0.001$; Figs. 1 and 2$)$. As opposed to CRC samples, G12C was the most common mutation in $K R A S$, in 346 cases (7.4\%), followed by G12V in 206 (4.4\%) and G12D in 188 (4.0\%). Mean age of KRAS G12C patients was 67.0 years (SE 0.486), and half were males (50.0\%). In contrast to CRC data, gender was not associated with KRAS mutation status $(p=0.229)$. On the other hand, significant associations were described between KRAS status, region $(p=0.003)$, and age $(p<$ $0.001)$. The frequency of KRAS G12C was higher in the South and Southeast regions (8.2 and 8.1\%, respectively), as opposed to 5.1 and $3.6 \%$ in the Northeast and North, 
A Colorectal cancer

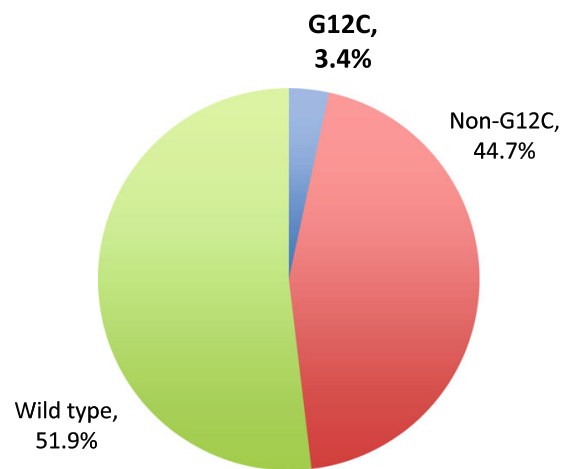

B

Non-small cell lung cancer

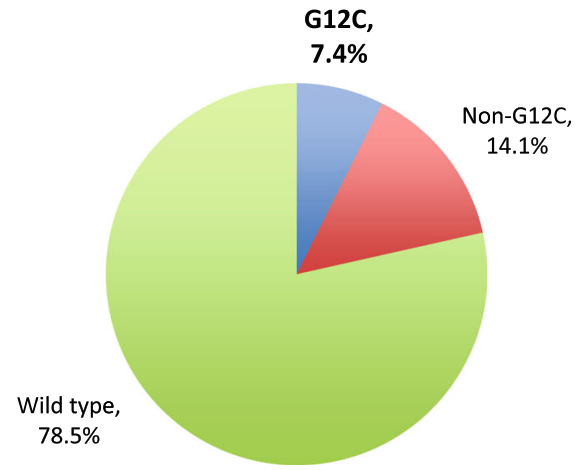

Fig. 1 Frequency of KRAS G12C and non-G12C mutations in colorectal (a) and non-small cell lung cancer (b)

respectively $(p=0.012)$. KRAS G12C was less frequent at younger ages: $2.0 \%$ or lower in patients younger than 50 years, as opposed to $7.2 \%$ or higher in patients older than 50 ( $p<0.001$; Fig. 4 and Supplemental Table 2).

\section{Co-occurring mutations}

Among NSCLC samples, EGFR mutations were detected in 1162 (24.8\%), BRAF in 167 (3.6\%) and NRAS in 27 (0.6\%). Most frequent EGFR mutations were exon 19 deletions in 611 samples (13.0\%), and exon 21 L858R point mutation in 326 (7.0\%). BRAF mutations involved codon 600 in 86 samples (1.8\%). KRAS G12C mutations were largely mutually exclusive with other driver mutations, however 21 cases (6.1\%) presented reportable comutations (Table 2). KRAS G12C co-existed with EGFR mutations in 10 cases, BRAF in 4 , and NRAS in 3. G12C co-occurred with other KRAS mutations in 5 cases. Nevertheless, 7 co-mutations were non-canonical, and 5 had an allelic frequency lower than 5\%; hence only 11 (3.2\%) NSCLC cases had clinically-relevant co-

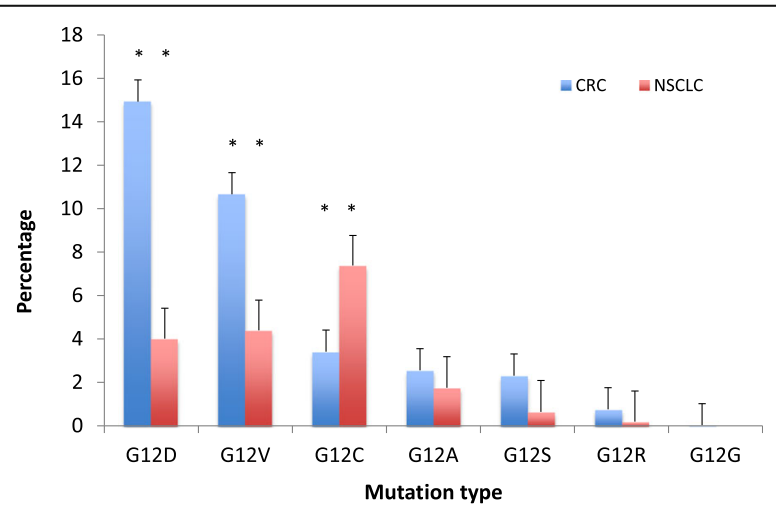

Fig. 2 Distribution of KRAS codon 12 mutations in colorectal (CRC) and non-small cell lung cancer (NSCLC) mutations. One sample presented with 3 mutated genes, including KRAS G12C (allelic frequency of 17\%), EGFR S768I (18\%), and BRAF V600E (5\%).

In CRC, 3 samples presented with co-existing mutations in KRAS: G12S and G12V (2 cases); G12V and G12C (1 case). NRAS status was available for 2261 patients, of which 187 (8.3\%) were mutated. The most frequent NRAS mutations involved codons 61 in 94 samples $(4.2 \%)$, codon 12 in $76(3.4 \%)$ and codon 13 in $14(0.6 \%)$. There was no overlap between KRAS and NRAS mutations among CRC samples.

\section{Discussion}

KRAS G12C has become a promising target for novel directed therapies in solid tumors [23], adding up a new role for routine KRAS testing. Given the lack of comprehensive and up to date information on the frequency of KRAS G12C and its characteristics of presentation, our group reviewed data from a large cohort of CRC and NSCLC samples (almost 10 thousand samples overall) submitted to KRAS testing in a clinical certified laboratory. Our data provide relevant input to guide future efforts in the field.

We described a frequency of KRAS G12C of $3.4 \%$ in CRC and 7.4\% in NSCLC, which is higher than rates of several other driver mutations currently in clinical use to guide targeted therapies [24]. In absolute numbers, these figures represent a large volume of patients that may benefit from novel directed therapies. The percentages described herein are in line with COSMIC database, where a frequency of 2.6 and $6.9 \%$ were reported in colon and lung adenocarcinomas, respectively [16, 25]. In Brazil, a comprehensive review of 8234 metastatic CRC patients found KRAS mutations in 31.9\% [26]. G12C was present in $7.9 \%$, but ranged from $7.1 \%$ in the Southeast to $12.2 \%$ in the North region [26]. The frequency of KRAS G12C was slightly higher in females 

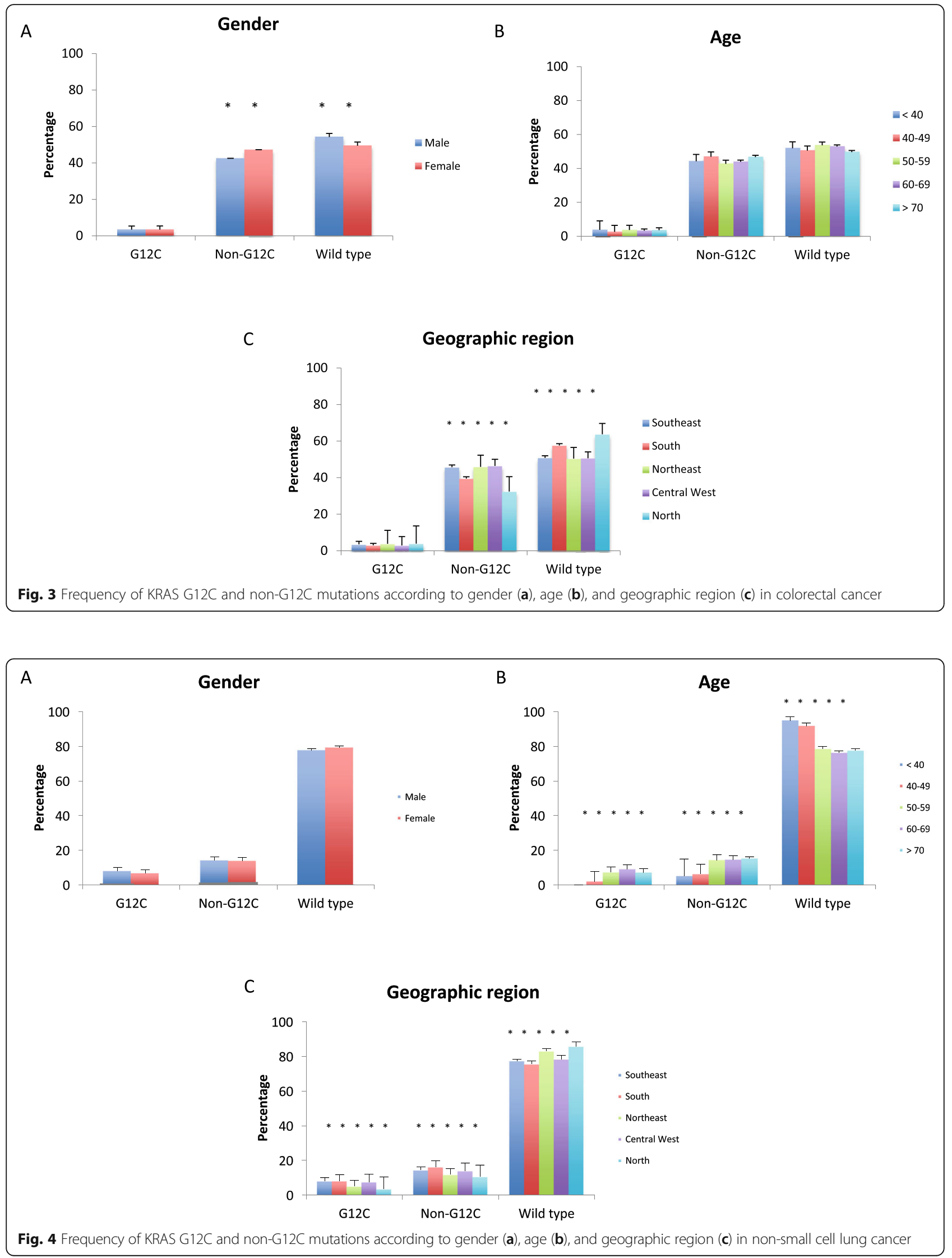
Table 2 Synchronic mutations co-occurring with KRAS G12C among NSCLC samples

\begin{tabular}{|c|c|c|}
\hline Genes & Amino acid change & Allelic frequency \%) \\
\hline \multirow[t]{5}{*}{ EGFR } & Exon 19 deletion ( 2 cases) & 19 and 2.5 \\
\hline & L858R (2 cases) & 4 and 2 \\
\hline & $\left.S 768\right|^{a}$ & 18 \\
\hline & G719N & 14 \\
\hline & $\mathrm{T} 725 \mathrm{M}^{\mathrm{b}} / \mathrm{A} 597 \mathrm{P}^{\mathrm{b}} / \mathrm{R} 831 \mathrm{H}^{\mathrm{b}} / \mathrm{N} 774 \mathrm{M}^{\mathrm{b}}$ & $49 / 13 / 3 / 7$ \\
\hline \multirow[t]{4}{*}{ KRAS } & G13D (2 cases) & 49 and 36 \\
\hline & G12S & 17 \\
\hline & G12V & 4 \\
\hline & $\mathrm{Q} 22^{\mathrm{b}}$ & 16 \\
\hline \multirow[t]{3}{*}{ BRAF } & V600E $\mathrm{E}^{\mathrm{a}}(2$ cases $)$ & 7 and 5 \\
\hline & V600K & 20 \\
\hline & $\mathrm{G} 464 \mathrm{E}^{\mathrm{b}}$ & 15 \\
\hline \multirow[t]{3}{*}{ NRAS } & Q61K & 24 \\
\hline & G13V & 14 \\
\hline & $\mathrm{E} 132 \mathrm{~K}^{\mathrm{b}}$ & NR \\
\hline
\end{tabular}

a 1 case of co-existing KRAS G12C, EGFR S768l, and BRAF V600E; ${ }^{\mathrm{b}}$ noncanonical mutations. Abbreviation: $N R$ not reported

than in males (8.6 and 7.1\%, respectively) [26]. No association was observed between age, gender, region, and KRAS G12C status in the current CRC cohort.

KRAS mutational data were described in a review of 513 lung adenocarcinomas from Brazilian patients profiled by NGS [27]. KRAS G12V and G12C were the most common mutations, in 6.9 and $6.7 \%$, respectively. Analysis of clinical and demographic characteristics was not provided. In a review of 5738 NSCLC samples from Latin America, KRAS mutations were found in $14 \%$ of samples, however no details were offered on KRAS G12C [28]. The current NSCLC data adds up by providing detailed KRAS analysis, and comparisons to clinical and demographic information. Our group found that KRAS G12C was significantly more frequent in older patients, as well as those from South and Southeast regions. A plausible explanation is the higher proportion of tobacco-related diseases at older age, hence linking this risk factor to KRAS G12C-related NSCLC. Also, South and Southeast are the regions with highest consumption of tobacco in the country [29], reinforcing the relationship between tobacco and KRAS G12C-mutant NSCLC. South and Southeast are also regions with the highest income in the country; molecular assessment may be more appropriate in these areas.

In agreement with COSMIC [25], KRAS G12C was the most frequent mutation in NSCLC, while KRAS G12D and G12V were the most common in CRC. The clinical observation that KRAS mutations differ in position and type of substitution according to cancer type is an intriguing, and yet unexplained phenomenon [16]. It has been suggested that distinct carcinogens may act differently to cause specific KRAS mutations and create selective pressures that will guide the process of tumor initiation in each tissue type [16]. For instance, KRAS G12C mutation is universally caused by a single nucleotide substitution at position $34, \mathrm{G}>\mathrm{T}$. This transversion is commonly found in mutational signatures associated with tobacco-related carcinogens in lung cancer [30]. On the other hand, KRAS G12D is caused by a G > A transition characteristic of CRC mutational signatures [30].

KRAS mutations are classic driver oncogenes, and rarely co-occur with other targetable mutations. In our dataset, 21 KRAS G12C-mutant NSCLC cases (6.1\%) presented reportable co-mutations, however only 11 (3.2\%) were canonical nucleotide variations with an allelic frequency of $5 \%$ or more. In a large database including 1078 KRAS-mutant NSCLC samples [31], EGFR mutations were found in $1.2 \%, B R A F$ in $1.4 \%$, and NRAS in $0.5 \%$. KRAS G12C was associated with a higher frequency of $E R B B 2$ amplification and ERBB4 mutations, while PTEN and BRAF mutations were less common than in the total cohort [31]. The finding that 2 or more gene mutations may co-occur within the same tumor likely reflects a multiclonal presentation that leads to tumor heterogeneity [31]. KRAS mutations may also emerge as a mechanism of secondary resistance to targeted therapies [32]. KRAS mutations commonly present alongside mutations in TP53, STK11, and KEAP1 and these co-mutations define distinct signature with potential clinical implications [33]. These genes were not assessed in our database.

The current study was based on laboratory reports; therefore limited clinical data were available. For instance, information on smoking status, disease stage, treatment, and outcomes were not provided. On the other hand, a large sample size was reached in a short and contemporary timeframe, which supports the reproducibility of our dataset. In addition, data analyzed was representative of the 5 geographic regions in the country. Brazil spans a large territorial extension and there may exist some degree of genetic background heterogeneity in the population. Differences in risk factors and disease presentation are expected, further supporting the strength of our results. It should be noted that North and Northeast regions were underrepresented in the current study, which may have caused an imbalance in the analysis. Future studies should focus on these regions to increase the power to confirm our findings. Lastly, modern sequencing platforms were applied in the current analysis, including pyrosequencing and NGS. The greater accuracy of these methods makes results more reliable than past publications in the field. 


\section{Conclusion}

The current dataset provides a comprehensive and contemporary overview of the molecular profile of $K R A S$ G12C in both CRC and NSCLC. KRAS G12C presents in frequencies higher than several other driver mutations, and may represent a large volume of patients in absolute numbers. KRAS testing should be considered in all CRC and NSCLC patients, independently of clinical or demographic characteristics, in order to improve enrolment in clinical trials.

\section{Supplementary Information}

The online version contains supplementary material available at https://doi. org/10.1186/s12885-021-07884-8

Additional file 1: Table S1 Distribution of colorectal cancer patients' characteristics according to KRAS status. Table S2 Distribution of nonsmall cell lung cancer patients' characteristics according to KRAS status.

\section{Acknowledgements}

none.

\section{Authors' contributions}

Conceived and designed the analysis: LHA, MCMF. Collected the data: BMS, LRL, SAFP, NPL, FSVM. Performed the analysis: LHA, BMS, LRL, SAFP, NPL, FSVM, MCMF. Wrote the main manuscript: LHA, MCMF. Reviewed the manuscript: LHA, BMS, LRL, SAFP, NPL, FSVM, MCMF. The author(s) read and approved the final manuscript.

\section{Funding}

none.

\section{Availability of data and materials}

Only limited and well described gene regions (hotspots) were sequenced for clinical purposes. Moreover, sequencing data generated were not meant for discoveries and no novel mutations were described. Therefore, sequencing data were not made available in a public database. The authors datasets analyzed during the current study are available from the corresponding author on reasonable request.

\section{Ethics approval and consent to participate}

The protocol was reviewed and approved by local Ethics Committee (Research Ethics Committee of the Minas Gerais Social Security Institute IPSEMG). A waiver for the informed consent was also approved by the Research Ethics Committee of the Minas Gerais Social Security Institute since all patients had previously signed an authorization for testing, and data were collected retrospectively through molecular reports review. No information capable of identifying patients was used.

\section{Consent for publication}

Since no detailed or identifiable data were utilized, a consent for publication was not applied.

\section{Competing interests}

The authors declare that they have no competing interests.

\section{Author details}

${ }^{1}$ Progenética, Grupo Pardini, Vespaziano, Brazil. ${ }^{2}$ Research \& Development Sector, Grupo Pardini, Vespaziano, Brazil. ${ }^{3}$ Instituto COI de Educação e Pesquisa, Rio de Janeiro, Brazil. ${ }^{4}$ Instituto Nacional de Câncer, Rio de Janeiro, Brazil.
Received: 13 November 2020 Accepted: 31 January 2021

Published online: 25 February 2021

\section{References}

1. Heinrich MC, Corless CL, Demetri GD, Blanke CD, von Mehren M, Joensuu $H$, McGreevey LS, Chen CJ, Van den Abbeele AD, Druker BJ, et al. Kinase mutations and imatinib response in patients with metastatic gastrointestinal stromal tumor. J Clin Oncol. 2003;21(23):4342-9.

2. Lynch TJ, Bell DW, Sordella R, Gurubhagavatula S, Okimoto RA, Brannigan BW, Harris PL, Haserlat SM, Supko JG, Haluska FG, et al. Activating mutations in the epidermal growth factor receptor underlying responsiveness of nonsmall-cell lung cancer to gefitinib. N Engl J Med. 2004;350(21):2129-39.

3. Macconaill LE, Garraway LA. Clinical implications of the cancer genome. J Clin Oncol. 2010;28(35):5219-28.

4. Shin SH, Bode AM, Dong Z. Addressing the challenges of applying precision oncology. NPJ precision oncology. 2017;1(1):28.

5. Cox AD, Der CJ. Ras history: the saga continues. Small GTPases. 2010;1(1):227.

6. Parada LF, Tabin CJ, Shih C, Weinberg RA. Human EJ bladder carcinoma oncogene is homologue of Harvey sarcoma virus ras gene. Nature. 1982; 297(5866):474-8

7. Almoguera C, Shibata D, Forrester K, Martin J, Arnheim N, Perucho M. Most human carcinomas of the exocrine pancreas contain mutant c-K-ras genes. Cell. 1988:53(4):549-54.

8. Smit VT, Boot AJ, Smits AM, Fleuren GJ, Cornelisse CJ, Bos JL. KRAS codon 12 mutations occur very frequently in pancreatic adenocarcinomas. Nucleic Acids Res. 1988;16(16):7773-82.

9. Bos JL, Fearon ER, Hamilton SR, Verlaan-de Vries M, van Boom JH, van der Eb AJ, Vogelstein B. Prevalence of ras gene mutations in human colorectal cancers. Nature. 1987;327(6120):293-7.

10. Forrester K, Almoguera C, Han K, Grizzle WE, Perucho M. Detection of high incidence of K-ras oncogenes during human colon tumorigenesis. Nature. 1987;327(6120):298-303

11. Rodenhuis S, van de Wetering ML, Mooi WJ, Evers SG, van Zandwijk N, Bos UL. Mutational activation of the K-ras oncogene. A possible pathogenetic factor in adenocarcinoma of the lung. N Engl J Med. 1987;317(15):929-35.

12. Barbacid M. ras genes. Annu Rev Biochem. 1987;56:779-827.

13. Simanshu DK, Nissley DV, McCormick F. RAS proteins and their regulators in human disease. Cell. 2017;170(1):17-33.

14. Cully M, Downward J. SnapShot: Ras Signaling. Cell. 2008;133(7):1292 e1291.

15. Vetter $\mathbf{I R}$, Wittinghofer $\mathrm{A}$. The guanine nucleotide-binding switch in three dimensions. Science. 2001;294(5545):1299-304.

16. Li S, Balmain A, Counter CM. A model for RAS mutation patterns in cancers: finding the sweet spot. Nat Rev Cancer. 2018;18(12):767-77.

17. Amado RG, Wolf M, Peeters M, Van Cutsem E, Siena S, Freeman DJ, Juan T, Sikorski R, Suggs $S$, Radinsky $R$, et al. Wild-type KRAS is required for panitumumab efficacy in patients with metastatic colorectal cancer. J Clin Oncol. 2008;26(10):1626-34.

18. van Zandwijk N, Mathy A, Boerrigter L, Ruijter $H$, Tielen I, de Jong D, Baas P, Burgers $S$, Nederlof P. EGFR and KRAS mutations as criteria for treatment with tyrosine kinase inhibitors: retro- and prospective observations in nonsmall-cell lung cancer. Ann Oncology. 2007;18(1):99-103.

19. Pennell NA, Arcila ME, Gandara DR, West H. Biomarker testing for patients with advanced non-small cell lung Cancer: real-world issues and tough choices. Am Soc Clin Oncol Educ Book. 2019:39:531-42.

20. Kalemkerian GP, Narula N, Kennedy EB, Biermann WA, Donington J, Leigh NB, Lew M, Pantelas J, Ramalingam SS, Reck M, et al. Molecular Testing Guideline for the Selection of Patients With Lung Cancer for Treatment With Targeted Tyrosine Kinase Inhibitors: American Society of Clinical Oncology Endorsement of the College of American Pathologists/ International Association for the Study of Lung Cancer/Association for Molecular Pathology Clinical Practice Guideline Update. J Clin Oncol. 2018; 36(9):911-9.

21. Canon J, Rex K, Saiki AY, Mohr C, Cooke K, Bagal D, Gaida K, Holt T, Knutson CG, Koppada N, et al. The clinical KRAS(G12C) inhibitor AMG 510 drives antitumour immunity. Nature. 2019:575(7781):217-23.

22. Hallin J, Engstrom LD, Hargis L, Calinisan A, Aranda R, Briere DM, Sudhakar N, Bowcut V, Baer BR, Ballard JA, et al. The KRAS(G12C) inhibitor MRTX849 provides insight toward therapeutic susceptibility of KRAS-mutant cancers in mouse models and patients. Cancer Discov. 2020:10(1):54-71.

23. Seton-Rogers S. KRAS-G12C in the crosshairs. Nat Rev Cancer. 2020;20(1):3. 
24. Sholl LM, Aisner DL, Varella-Garcia M, Berry LD, Dias-Santagata D, Wistuba II, Chen $\mathrm{H}$, Fujimoto J, Kugler K, Franklin WA, et al. Multi-institutional oncogenic driver mutation analysis in lung adenocarcinoma: the lung Cancer mutation consortium experience. J Thor Oncol. 2015;10(5):768-77.

25. Tate JG, Bamford S, Jubb HC, Sondka Z, Beare DM, Bindal N, Boutselakis H, Cole CG, Creatore C, Dawson E, et al. COSMIC: the catalogue of somatic mutations in Cancer. Nucleic Acids Res. 2019;47(D1):D941-7.

26. Gil Ferreira C, Aran V, Zalcberg-Renault I, Victorino AP, Salem JH, Bonamino $\mathrm{MH}$, Vieira FM, Zalis M. KRAS mutations: variable incidences in a Brazilian cohort of 8,234 metastatic colorectal cancer patients. BMC Gastroenterol. 2014;14:73.

27. Mascarenhas E, Gelatti AC, Araújo LH, Baldotto C, Mathias C, Zukin M, Werutsky G, Pacheco P, Gomes R, de Castro G Jr, Cordeiro de Lima VC. Comprehensive genomic profiling of Brazilian non-small cell lung cancer patients (GBOT 0118/LACOG0418). Thorac Cancer. 2020. https://doi.org/1 0.1111/1759-7714.13777. Epub ahead of print. PMID: 33314759.

28. Arrieta O, Cardona AF, Martin C, Mas-Lopez L, Corrales-Rodriguez L, Bramuglia G, Castillo-Fernandez O, Meyerson M, Amieva-Rivera E, CamposParra AD, et al. Updated frequency of EGFR and KRAS mutations in NonSmall-cell lung Cancer in Latin America: the Latin-American consortium for the investigation of lung Cancer (CLICaP). J Thor Oncol. 2015;10(5):83843.

29. INCA: Data and smoking numbers. 2019 https:/www.incagovbr/en/observa tory-of-the-national-policy-on-tobacco-control/data-and-smoking-numbers, Accessed in 8 Aug 2020.

30. Alexandrov LB, Nik-Zainal S, Wedge DC, Aparicio SA, Behjati S, Biankin AV, Bignell GR, Bolli N, Borg A, Borresen-Dale AL, et al. Signatures of mutational processes in human cancer. Nature. 2013;500(7463):415-21.

31. Scheffler M, Ihle MA, Hein R, Merkelbach-Bruse S, Scheel AH, Siemanowski J, Bragelmann J, Kron A, Abedpour N, Ueckeroth F, et al. K-ras mutation subtypes in NSCLC and associated co-occuring mutations in other oncogenic pathways. J Thor Oncol. 2019;14(4):606-16.

32. Oxnard GR, Hu Y, Mileham KF, Husain H, Costa DB, Tracy P, Feeney N, Sholl LM, Dahlberg SE, Redig AJ, et al. Assessment of resistance mechanisms and clinical implications in patients with EGFR T790M-positive lung Cancer and acquired resistance to Osimertinib. JAMA Oncol. 2018;4(11):1527-34.

33. Skoulidis F, Byers LA, Diao L, Papadimitrakopoulou VA, Tong P, Izzo It Behrens C, Kadara H, Parra ER, Canales JR, et al. Co-occurring genomic alterations define major subsets of KRAS-mutant lung adenocarcinoma with distinct biology, immune profiles, and therapeutic vulnerabilities. Cancer Discovery. 2015;5(8):860-77.

\section{Publisher's Note}

Springer Nature remains neutral with regard to jurisdictional claims in published maps and institutional affiliations.

Ready to submit your research? Choose BMC and benefit from:

- fast, convenient online submission

- thorough peer review by experienced researchers in your field

- rapid publication on acceptance

- support for research data, including large and complex data types

- gold Open Access which fosters wider collaboration and increased citations

- maximum visibility for your research: over $100 \mathrm{M}$ website views per year

At $\mathrm{BMC}$, research is always in progress.

Learn more biomedcentral.com/submissions 